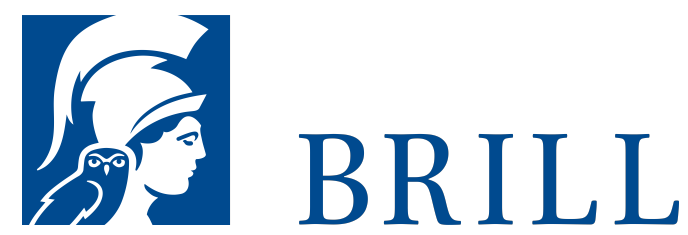

\title{
Funktionen der Lyrik
}

Author: Rüdiger Zymner

„Wozu Lyrik?“ - so lautet die Leitfrage dieses Buches. Die Theorie der Lyrik öffnet sich mit ihr den kulturell-historischen und den anthropologischen Dimensionen des Gattungskonzeptes und überschreitet das basale Niveau der Bestimmung von Grundbegriffen. Das Buch knüpft an „Lyrik. Umriss und Begriff" (2009) an und entwickelt ein Konzept der ,Funktion', das an Beispielen der Lyrik von der Präantike bis in die jüngste Gegenwart untersucht wird. Es thematisiert Shakespeares ,Sonette' ebenso wie Petrarcas ,Canzoniere', die Lyrik Rimbauds ebenso wie diejenige Goethes, Fontanes, Brechts oder auch Thomas Klings und Durs Grünbeins; es wendet sich dem lyrischen Gebet (Dietrich Bonhoeffer) ebenso zu wie dem Chanson (Jacques Brel), der, alltäglichen' Gelegenheitslyrik ebenso wie dem anspruchsvollen lyrischen Kunstwerk - und es schließt mit evolutionsbiologischen und kulturwissenschaftlichen Überlegungen zur anthropologischen Funktion von Lyrik.

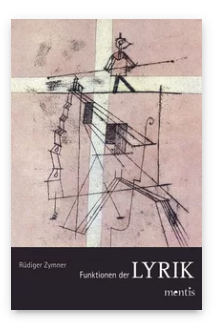

Pages: 363

Seiten

Language:

German

Subjects:

General,

Literature and

Cultural Studies

Publisher: Brill |

mentis

E-Book (PDF)

Released online:

23 Aug 2013

ISBN: $978-3^{-}$

89785-971-5

List price

Paperback

Publication date:

23 Aug 2013

ISBN: 978-3-

89785-820-6

List price 
For more information see brill.com

Order information: Order online at brill.com +44330 333 0049 | customerservices@brill.com Submission information: brill.com/authors

Titles published by Brill | Fink, Brill | mentis or Brill | Schöningh: +49(o)715413279216| brill@brocom.de 